\title{
Core components of three functions of clinical supervision in undergraduate medical education during a clinical course
}

\author{
Soleiman Ahmady ${ }^{1 * \oplus}$, Masoumeh Seidi²
}

${ }^{1}$ Shahid Beheshti University of Medical Sciences, Tehran, Iran; Research Affiliated Faculty at Department of LIME, Karolinska Institutet, Sweden.
${ }^{2}$ Virtual School of Medical Education and Management, Shahid Beheshti University of Medical Sciences, Tehran, Iran.
${ }^{*}$ Correspondence to: Soleiman Ahmady (E-mail: soleiman.ahmady@gmail.com)
(Submitted: 12 November 2020 - Revised version received:26 January 2021 - Accepted:04 February 2021 - Published online: 26 April 2021)

\begin{abstract}
Objective Attending physicians must holistically consider medical trainees. The quality control aspects of clinical practices and skills development as well as increase in trainees' knowledge and alleviated stress. Current clinical supervision does not meet the needs of trainees. This study aimed to identify the components of functions of clinical supervision in undergraduate medical education. The process of the literature review was implemented in five phases following the method developed by Carnwell and Daly. The scope of the review was limited to clinical supervision of medical trainees and the functions of clinical supervision models.

Methods Using the keywords in combination and separately, they were searched in the databases of PubMed, ERIC, Scopus, and WOS from 1970 to 2019.

Results A total number of 49 documents (Policy /Guideline/ Standard) and 19 articles (functions of clinical supervision) were obtained. Conclusions To make efforts to empower attending physicians in the clinical supervision functions and these functions be simultaneously applied for trainees supervision.

Keywords Clinical supervision, Medical trainee, Model, Policy, Guideline, Standard.
\end{abstract}

\section{Introduction}

Supervision term in the Cambridge vocabulary is defined as the act of looking at the person or activity and making sure that everything is done properly and safely. Supervision in two terms of overlapping circles can be focused on the development of performance, or both. ${ }^{1}$ Kilminster (2007) noted that supervision "the provision of guidance and feedback on substances of personal, professional, and educational development in the background of a trainee's experience of providing safe and appropriate patient care". ${ }^{2}$ Undergraduate medical education (UGM) includes theoretical and clinical knowledge designed to provide efficient human resources to meet a community's needs. ${ }^{3}$ The terms of clinical education refer to the acquisition of supervised professional skills. ${ }^{4}$ The purposes of clinical supervision are ensuring patient safety/care, educating the trainee, promoting high standards, identifying trainee problems, monitoring trainee progress, and supporting the trainee. ${ }^{2}$ In the systematic review, a study conducted from 2002 to 2014, results show that the competencies of general physicians in assessed skills were not desirable. ${ }^{5}$ Problems in UGM display the differences in the education level between universities and weaknesses in providing teaching by the residents. ${ }^{6}$ Also, several clinical supervisors do not have an efficient performance in teaching hospitals which needs to be more evaluated and improved. ${ }^{7}$ According to the literature, the availability of supervision for medical trainees and specializing physicians is inadequate. ${ }^{8} \mathrm{New}$ curriculums strive to move from time-based model to the current trend towards competency-based medical education (CBME). ${ }^{9}$

Some trainees have a concern about job future, ${ }^{6,10}$ tests time condition, ${ }^{11}$ on-call and rotation schedules in the hospital and preparation for residency, ${ }^{12}$ fear of lack of knowledge and lack of skill, and criticism of trainee activities by clinical educator, ${ }^{13}$ that has made them psychical and spiritual problems. They use many mechanisms to deal with stress, but the using of many negative coping strategies. High levels of stress and anxiety during the clinical course can affect the professional effectiveness of trainees and reducing their attention and concentration, impair their decision-making skills, and reduce the trainee's ability to communicate effectively with patients. ${ }^{11}$ Stress has negative effects on trainees learning and clinical success, and their proper functioning of overshadowing. ${ }^{13}$ The availability and emotional support of the supervisor provided a positive relationship with learning progress and increased trainee satisfaction. ${ }^{14}$ Therefore, trainees require pastoral, and spiritual care, especially when trainees experience a crisis in their personal or professional life. ${ }^{1}$ The pattern of clinical supervision of medical trainees in Iran includes a range of internships to attending physicians. The attending physicians or faculty members and senior residents provide supervision for junior residents and internship in a hierarchical supervisory structure. The supervision level is reduced by attending physicians for UGM. Current supervision doesn't meet the needs of medical trainees.

There is an agreement in the general literature that supervision has three functions managerial or administrative, educative, and supportive. ${ }^{2}$ The idea of three functions or roles of supervision is reflected across professions; for example, nursing, ${ }^{15,16}$ social work, ${ }^{17,18}$ and recommended for the use in medicine. ${ }^{2,8}$ The managerial function is responsible for the trainee's casework and ensuring that the supervisee complies with the rules, and norms of organizations, in which the work is carried out. ${ }^{19}$ The educational function is developing skills and enhancing understanding. ${ }^{20}$ The supportive function acknowledges the emotional effects on an individual of work, and in particular of work with people in distress. ${ }^{19}$ Each of the functions may come to the fore or remain in the background in clinical supervision and circumstances. ${ }^{21}$

There is needing to expand clinical supervision of medical trainees, and students must be considered about a general and holistic view, but only through providing and teaching several 
skills and competencies. Moreover, supervisors must not expect students to abide by several laws and regulations, and other aspects as individuals should not be overlooked. There is no similar study on the application functions of clinical supervision to medical students in the clinical setting. The purpose of this study was a response to the question being investigated. What are the components, and the characteristics of three functions associated with the clinical supervision of medical trainees in the UGM?

\section{Methods}

A critical review was utilized as the research design. To note, the main purpose of this literature review was to appraise and synthesize the current state of knowledge related to the topic under investigation, as a means of identifying gaps of knowledge addressed by this new study. ${ }^{22}$

In this critical review, the researcher did not claim to cite all relevant articles in the desired field, but rather morally committed to presenting different views in a fair manner. ${ }^{23}$ In this study, the process of conducting the literature review was implemented according to Carnwell and Daly. ${ }^{22}$

The search strategy was comprised of two steps. At the first step, the search was done by focusing on the following keywords, separately and in combination: Clinical Supervision (AND) ("Medical Student*" OR Trainee* OR Clerkship) (AND) (Policies or Guidelines or Standards).

Besides, manual library searches along with free internet ones were performed. All the available sources were thus identified and each database was respected by the instructions specified for it. The search in the databases of Web of Science (WOS), Scopus, PubMed, Google Scholar, and the Education Resources Information Center (ERIC) on clinical supervision of UGM was accordingly done on articles published from 1970 to 2019. After excluding the irrelevant studies, a total number of 49 documents (namely, 42 policies, 4 guidelines, and 3 standards) were selected to review, as shown in the PRISMA flow diagram (Fig. 1).

Forty-nine (49) documents were reviewed by the researchers in their full-texts. Two criteria were also considered for the final selection of the policies, guidelines, and standards. being updated over the last 10 years and considering aspects such as supervisor, trainee, context, supervisor-supervisee relationship, and tasks. ${ }^{24,25}$ the number of policies, guidelines, and standards at medical schools were correspondingly written very briefly and if they had pointed out a new component, that component was extracted. After assessing the given documents with the above-mentioned criteria, 30 documents remained.

At the second step, studies using the models of clinical supervision functions were searched. The searches correspondingly revealed the models of clinical supervision functions employed in numerous studies and resources associated with nursing, social work, and other fields. From the obtained articles, 19 studies were selected (Tuck 2017, Basa 2017, Gillieatt 2014, Beddoe 2012, Turner 2011, Hughes 2010, Gardner 2010, Brunero 2008, Clark 2006, Scaife 2003, Sloan, Watson 2002, Morrison 2001, Morton-Cooper 2000, bowels 1999, Cutcliffe 2010, Butterworth 1997, Butterworth 1996, Jones 1996, Erera 1994). Then, 19 studies were scrutinized in relation to the functions of clinical supervision. The definition, characteristics, and components of each function of clinical

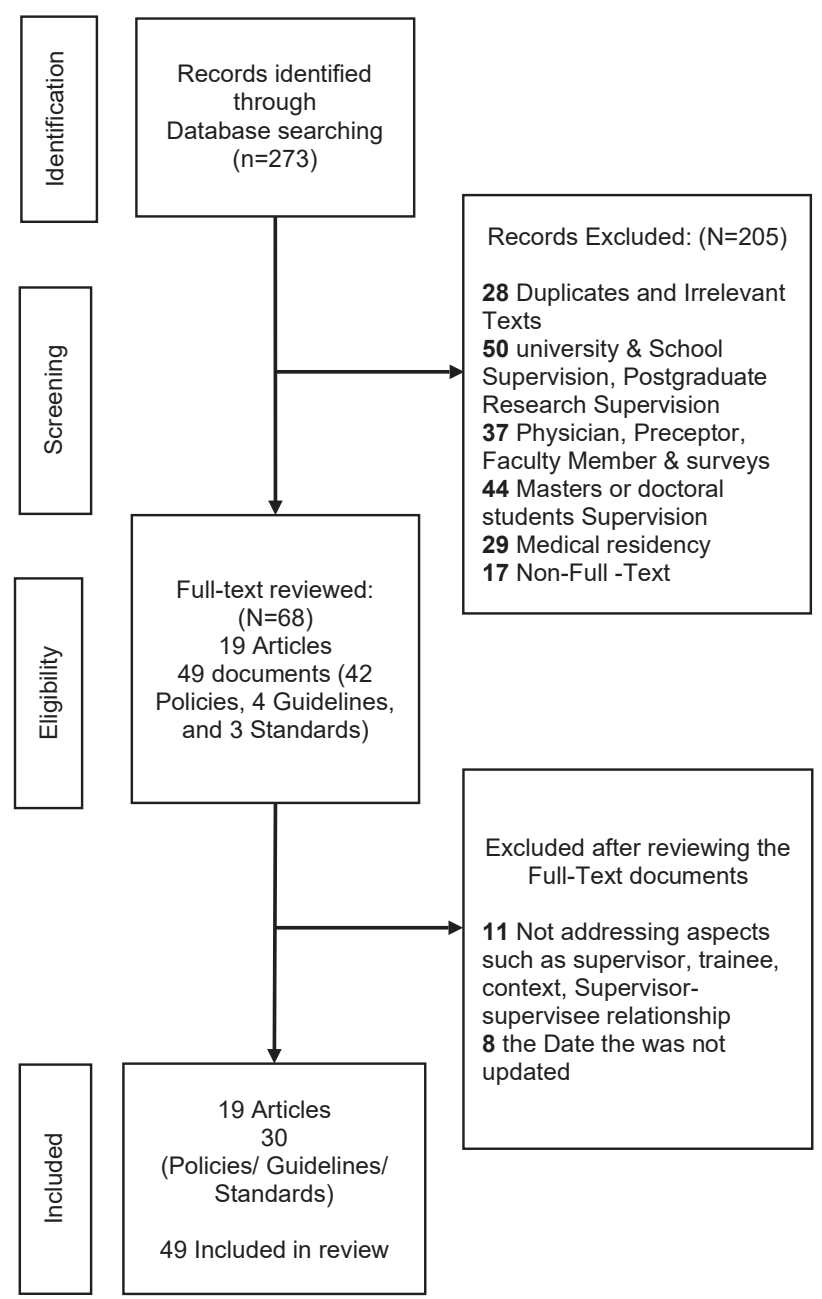

\section{Fig. 1 PRISMA flowchart.}

supervision were extracted separately from the studies. Three functions of clinical supervision were defined separately.

\section{Results}

\section{The main components of documents: Clinical Supervision for medical trainees in medical schools}

The U.S. Department of Education identifies the Liaison Committee on Medical Education (LCME) as an accrediting agency for medical education programs leading to the MD degree. ${ }^{26}$ The committee on the Accreditation of Canadian Medical Schools (CACMS) standards provide for the quality of medical education programs leading to the M. D. ${ }^{27}$ In Standard No. 9-3 Two, Committees emphasizing on Clinical Supervision for medical students, and medical schools have attempted to prepare this standard 9-3 clinical supervision in the form of policy/guideline/standard. Most medical schools wrote in the form of policy.

A researcher designed a checklist of 30 documents and obtained clinical supervision for medical students. The document of each medical school was compared with the checklist. To avoid the lengthy text of the documents and prevent readers' fatigue, a sample of 10 medical schools (including University of MC Gill Faculty Of Medicine, ${ }^{28}$ University of 
Alberta, ${ }^{29}$ University of British Columbia, ${ }^{30,}{ }^{31}$ University of Boston School Of Medicine (BUSM), ${ }^{32}$ University of Nebraska College of Medicine, ${ }^{33}$ University of Florida Atlantic Charles E. Schmidt College Of Medicine (FAU COM), ${ }^{34}$ University of Washington School Of Medicine (UWSOM), ${ }^{35}$ University of North Carolina School Of Medicine (UNC SOM), ${ }^{36}$ University of Minnesota Medical School (UMMS), ${ }^{37}$ and University of Pennsylvania ${ }^{38}$ are listed in Table 1.

While reviewing the General Medical Council (GMC) standards, ${ }^{39}$ the generic standards for training by the Postgraduate Medical Education and Training Board (PMETB), ${ }^{40}$ and a guideline of the Royal Australian College of General Practitioners (RACGP) ${ }^{41} 15$ components were identified. These components were then added to the ones obtained from the aforementioned 30 medical schools (Table 2). Accordingly, a total number of 25 components were achieved.

\section{Characteristics of three function of clinical supervision}

The models for functions of clinical supervision have been explained in a theoretical and conceptual manner. Models that divided the function of clinical supervision into three functions, ${ }^{42}$ including Bridget Proctor (1986): formative, restorative, and normative, ${ }^{43}$ and emphasis on supervisee. Alfred Kadushin (1976): educational, supportive, and managerial/ administrative, ${ }^{44}$ and emphasis on supervisor. ${ }^{45}$ Hawkins and Shohet (2006): developmental, resourcing, and qualitative, ${ }^{46}$ emphases on both supervisor and supervisee. ${ }^{47}$
Proctor's model (1986) provides a good framework and is one of the most cited models in the UK nursing literature. ${ }^{48}$ Proctor's model has been criticized for lack of detail in its application. However, its positive that allows space for the necessary creativity that developing clinical practice requires. ${ }^{49}$ Gillieatt (2014) suggests that adapting Proctor's model for student clinical supervision is relevant across a broad range of health disciplines and clinical areas. ${ }^{50}$

\section{Managerial/Normative/Qualitative}

This function relates to the accountability of supervisees' clinical performance and clinical outcomes to ensure ethical quality services. ${ }^{42}$ Maintaining standards of practice, care, and professionalism providing honest feedback and constructive criticism, ${ }^{46}$ assessment, ${ }^{50-52}$ quality control aspects of clinical practice, ${ }^{48}$ organizational responsibility, ${ }^{53}$ ensure the identification and self-assessment of professional and ethical competence. ${ }^{20}$

\section{Educational/Formative/Developmental}

This function focuses on learning, training, and teaching. ${ }^{42}$ Evaluating observed performance, ${ }^{54}$ responsibility for the development of the student, ${ }^{43,54}$ and the ongoing monitoring and evaluating of the student at certain times at end of the course or point of promotion, ${ }^{43}$ skills development, and increasing the trainee's knowledge, ${ }^{19,44,48,50,52,53}$ learning through reflection and sharing good practice, opportunities for teaching and skill acquisition, ${ }^{46}$ enabling personal and professional development. ${ }^{52}$

Table 1. The components of clinical supervision policy/guideline/standard in $\mathbf{1 0}$ medical schools.

\section{School Of Medicine}

Components

Duties or expectations or responsibilities of clinical trainees

Setting purpose

Levels of clinical supervision

Defining Clinical supervisor

Recommendations for the safety of patients and trainees

Assessment of Clinical trainees

Expectations or roles or responsibilities of the supervisor

Delegate responsibility to trainees

Report clinical trainees concerns of the supervision process

Consider professional and ethical standards

Monitoring of supervision program

Determinant factors to require the amount of supervision

Provide feedback and constructive criticism on performance

How requests help Trainees in Clinical Situations

Delineate work procedures of trainees

The position of clinical trainees in the treatment team
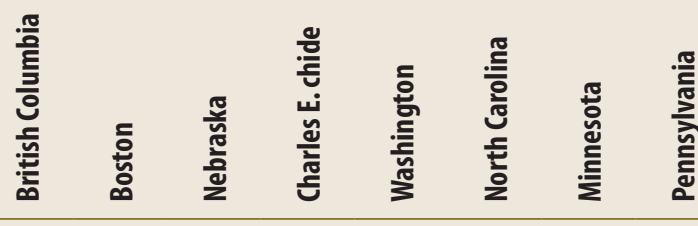

\begin{tabular}{|c|c|c|c|c|c|c|c|c|c|}
\hline 1 & 1 & 1 & 1 & 1 & 1 & 1 & 1 & 1 & 1 \\
\hline 1 & 1 & 1 & 0 & 1 & 1 & 1 & 1 & 1 & 1 \\
\hline 1 & 0 & 1 & 1 & 1 & 1 & 1 & 1 & 1 & 1 \\
\hline 1 & 0 & 1 & 1 & 1 & 1 & 1 & 1 & 0 & 1 \\
\hline 1 & 1 & 1 & 1 & 1 & 0 & 0 & 1 & 1 & 1 \\
\hline 1 & 1 & 1 & 0 & 1 & 0 & 1 & 1 & 1 & 1 \\
\hline 1 & 1 & 1 & 0 & 1 & 0 & 0 & 1 & 1 & 1 \\
\hline 0 & 1 & 1 & 1 & 0 & 1 & 1 & 1 & 1 & 0 \\
\hline 1 & 0 & 0 & 1 & 1 & 0 & 1 & 1 & 0 & 1 \\
\hline 1 & 0 & 1 & 1 & 0 & U & 0 & 1 & 0 & 1 \\
\hline 1 & 0 & 1 & 1 & 1 & 0 & 0 & 0 & 0 & 1 \\
\hline 1 & 0 & 1 & 0 & 0 & 1 & 0 & 0 & 1 & 1 \\
\hline 0 & 0 & 1 & 0 & 1 & 0 & & 1 & 0 & 0 \\
\hline 1 & 1 & 0 & 0 & 0 & 1 & & 0 & 0 & 0 \\
\hline 0 & 0 & 1 & 1 & 0 & 0 & & 0 & 1 & 0 \\
\hline 1 & 0 & 0 & 0 & 0 & 0 & 0 & 0 & 0 & 1 \\
\hline
\end{tabular}




\begin{tabular}{|c|c|}
\hline Function & Components \\
\hline \multirow[t]{10}{*}{ Managerial supervision } & Determine the theory or conceptual framework \\
\hline & Define ethical, professional and legal standards in the clinical environment \\
\hline & Existence of a contract/agreement between the supervisor and trainee \\
\hline & Eligible manpower to be the supervisor \\
\hline & Determine the knowledge, skills, and competencies of a clinical supervisor \\
\hline & Expectations, duties and responsibilities of the clinical supervisor \\
\hline & Expectations, responsibilities and tasks of clerkship/internship \\
\hline & Delineate work procedures for clerkship/internship \\
\hline & Assessment or evaluation of clerkship/internship \\
\hline & Monitoring of education programs \\
\hline \multirow[t]{7}{*}{ Educational supervision } & Setting educational goals \\
\hline & Supervisor and students as teacher (intern, resident, and fellow) training \\
\hline & Determining to achieve the minimum competencies expected in the clerkship/internship course \\
\hline & Determinant factors of the amount of supervision required trainees \\
\hline & Presentation feedback and constructive criticism \\
\hline & Determine progressive levels of clerkship/internship \\
\hline & Provide reflection opportunities during and after the action \\
\hline \multirow[t]{8}{*}{ Supportive supervision } & The type of relationship between the supervisor and trainee \\
\hline & Safety of trainees in all clinical settings \\
\hline & Design flowchart for request help trainees in clinical situations \\
\hline & $\begin{array}{l}\text { Guidelines for report trainees concerns about the clinical, administrative, vocational and } \\
\text { educational affairs and supervision process }\end{array}$ \\
\hline & Planning for real-time supervision (during activity) \\
\hline & Considering personal needs and balance between work and life trainees \\
\hline & Existence activities to increase the confidence, well-being, and creativity of trainees \\
\hline & Define the position of clerkship/internship in the treatment team \\
\hline
\end{tabular}

\section{Supportive/Restorative/Resourcing}

This function provides support to supervisee's emotional responses ${ }^{42}$ adequately refreshed and recreative, ${ }^{52}$ to alleviate the stress, ${ }^{54,55}$ well-being, ${ }^{50,53}$ self-care, ${ }^{50}$ acknowledges the emotional effects on the individual work, and in particular work with people in distress, ${ }^{19}$ real-time supervision, positive achievements, coping for adverse incidents. ${ }^{56}$ Space for trainees to vent their feelings in a listening environment. ${ }^{46}$ Student support is complemented by the form of peers and peer groups, and the existence of personal tutors or educational advisers, ${ }^{52}$ facilitates the discharging of emotions and recharging of energies. ${ }^{20}$

\section{Discussion}

This study aimed to identify the characteristics and the components of clinical supervision functions of medical trainees during a clinical course.

It is of note that supervision in the education system is regarded as an umbrella term, ${ }^{1,21,57}$ covering all one-on-one professional encounters. ${ }^{21}$ There are also some terminologies and words, which contain dimensions of supervision as their core concepts, ${ }^{57}$ such as clinical supervision, educational supervision, remedial supervision, mentoring, preceptorship, and coaching. In this sense, each term can have different effects on educational goals and specific characteristics. ${ }^{1,21}$

In this respect, educational supervision refers to regular supervision taking place in the context of a recognized training to establish learning needs and to review progress. It is also the most common one among senior and junior postgraduate residents. ${ }^{1,58}$ As well, remedial supervision is a subset of educational supervision aimed at retraining. ${ }^{21}$ Clinical supervision is also regarded as an interchange between practicing professionals to assist the development of professional skills. ${ }^{21}$ Mentoring is likewise rooted in socialization theories in psychology. The focus of these theories is on how individuals learn new behaviors and social roles. ${ }^{59} \mathrm{~A}$ preceptorship represents a time-defined relationship with externally defined objectives, and has the teaching of a novice in the proficiencies of a new role as its goal. ${ }^{60}$ Coaching is also a process that can guide students 
towards performance improvement. ${ }^{61}$ It is noteworthy that preceptorship, ${ }^{21,62}$ and coaching are a subset of mentoring. ${ }^{63,64}$

In the literature review, the types of supervision had been cited in these articles (e.g. Clark, 2006; Launer, 2014; Scaife, 2003; Morton-Cooper, 1997; Jarvis, 2004; Rousseau 2008). The researchers in the present study also designed a form for different types of supervision in medical education (Fig. 2).

Studies show that clinical and educational supervision are effective as they apply mentoring principles and characteristics. ${ }^{65,66}$ The mentoring during supervision of a fortuitous relationship can also foster the development of medical students. ${ }^{58}$ It seems that supervision and mentoring are far from being mutually exclusive and they are potentially complementary in many respects. Although the mentoring role signals a concerted emphasis on support, encouragement, advocacy, and collegial connection, supervision may encompass a distinct mandate for evaluation and gatekeeping. ${ }^{66,67}$ The effectiveness of supervision can be accordingly improved during formal meetings, augmenting quality of feedback and ensuring that occurrence of regular mentoring dialogues would be highly valuable. $^{58}$

With regard to the review of 30 documents (i.e., policies, guidelines, standards) on clinical supervision of medical students, it seems that all medical schools have attempted to compose and adhere to standard no. 9.3 of clinical supervision of medical students, introduced in the LCME and the CACMS, in a brief manner or in detail. According to the review of the given documents, it seems that many have been merely designed in response to agencies for the accreditation of medical education programs. The focus of the components are also laid more on enforcing student regulations and discipline and concentrated on duties, responsibilities, and expectations of supervisors, to ensure the supervision process has been presented. These tasks dominate and focus supervision on compliance with organizational and legislative requirements. Within these situations, the underlying power relations are arranged to privilege managerial functions at the expense of educational and supportive functions, which result in trainees' displeasure and possibly compromised supervision outcomes. ${ }^{68,69}$ Therefore, it is imperative that all three supervision functions are simultaneously applied.

Besides, two committees (namely, LCME and CACMS) have thus far reviewed the requirements of supervision of the GMC for the school of medicine. ${ }^{39}$ In this document, the responsibility of students are achieving all outcomes as well as

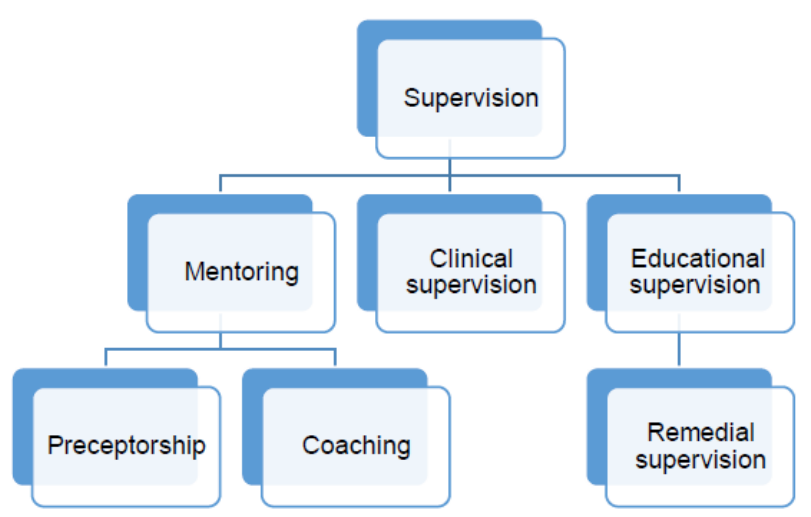

Fig. 1 Relationship between types of supervision in medical education. ensuring patient safety by working within the limits of their competence. ${ }^{70}$ The elements in the supervision of medical trainees have been thus announced by the PMETB and GMC as guaranteeing trainee safety, ensuring an appropriate level and amount of clinical duties, as well as monitoring progress, feedback on performance, and provision of career advice..$^{71,72}$

The RACGP has also guided supervision and support trainees to maintain general practitioners' teaching standards. ${ }^{41}$ Accordingly, supervisors' roles, mentioned for trainees' supervision and support, take account of assisting students to understand the requirements of the education course and providing direct observation sessions, which should be at an appropriate level considering the students' knowledge and experience, ensuring that students are introduced to all members of staff. Moreover, the given roles are also related to taking direct and principal responsibility of patients and being physically present at the workplace at all times, whilst students are providing clinical care as the ultimate management of patients. $^{41}$

Iranian Doctor of Medicine (M.D.) program differs from that in the United States and Canada. In these countries, students complete an undergraduate university degree before enrolling in medical schools. The curriculum is also characterized by $2+2$ structures for basic sciences and clinical years. ${ }^{73}$ In Iran, students enter in medical schools from high school. The curriculum is additionally characterized by $3+3.3$ for basic sciences and clinical years. In addition, clinical courses have two phases, clerkship (minimum of 21 months) and internship (18 months). These two phases in some of the supervision components must be separately defined on basic educational goals as experiences, expectations, and needs of trainees. In many little policies, guidelines, and standards, there are difference between clerkship and internship. For example, roles and work procedures for medical students, ${ }^{34}$ at Charles E. Schmidt College of Medicine or orders in hospital medical records, teaching and learning, observation, assessment, and feedback at Columbia Faculty of Medicine are divided into two groups: medical students in 1 and 2 and 3 and 4 years. ${ }^{30}$ Accordingly, the components that should be provided for the clerkship and internship courses were separately identified (Table 2). On the other hand, clinical supervision function models demonstrated that each function had different characteristics.

Each function is also part of the supervisory activities for medical students because each function has its own definition and includes specific tasks and the students must benefit from all these components. Management supervision blind spots as well as poor practices are correspondingly intended to ensure corporate ethics and client safety standards. ${ }^{74}$ Educational supervision can thus provide knowledge and skills needed to perform effective services and is associated with cognitive aspects and learning in trainees, ${ }^{44,75}$ training and development, as well as performance evaluation observed. ${ }^{54}$ Besides, supportive supervision indirectly enhances effective emotional states and promotes resilience to stress. ${ }^{76}$ So, in supervisory support, supervisors provide the space for trainees to reflect on the impact of work on their personal and professional well-being. ${ }^{74}$

Twenty-five (25) components were broken down into managerial supervision, educational supervision, and supportive supervision. It should be noted that these three functions were challenging as they were not all mutually exclusive and a degree of overlap was inevitable (Table 2). 
Attending physicians should be thus given necessary training for the supervisory roles, knowledge of supervision models, trainees' developmental levels, together with adult learning principles. Clinical supervision training can accordingly facilitate improved patient outcomes, supervisor competence, and trainee satisfaction.

In this line, Curtin University course provide supervision training to allied health, nursing, and medical staff. This training course is comprised of five 1-day introductory and three 4-day advanced workshops. The 1-day training provides an overview of an expanded version of the Proctor's model with its own roots in the Kadushin's work on social work supervision..$^{50}$

Medical students are thus expected to benefit more from clinical supervision, to achieve a sense of personal support and well-being, to increase knowledge and awareness of possible solutions to clinical problems, to boost confidence, to reduce emotional stress and burnout, and to enhance participation in reflection practices. ${ }^{54}$

However, these models address three central supervision functions, but suggest the need to take account of other factors. This means, expanding the model so that supervisors become empowered to match the supervision tasks to the developmental stage of trainees, critically reflecting on human diversity such as culture, ethnicity, disability, socioeconomic status, religion, and life experiences.

\section{Conclusion}

The perception of clinical supervision is yet a monitoring tool. It is apparent that managerial/administrative role is much more extensive and it mostly includes assuming responsibilities for trainees' work and ensuring that they have conformed to rules and norms of organizations. It seems that two educational and supportive roles have faded or disappeared due to managerial roles.

There are also efforts to define functions for clinical supervision in other field of medical education in which trainees can spend part of their education at patient bedside. The researchers reviewed documents to achieve objective and tangible characteristics for functions associated with clinical supervision of medical trainees. The results of the present study on clinical supervision function models demonstrated that each function had different characteristics, and three supervisions were separately defined.

The main purpose was to help graduate a person being without any stress and concerns, as a qualified doctor, a respectable citizen, and a competent manager, etc. It is thus necessary that the three clinical supervision functions be simultaneously applied by supervisors. It is recommended to make efforts to empower attending physicians in clinical supervision functions and developing tools for student evaluation based on these three functions. The results of this study should be operationally implemented for medical students to detect challenges and inconsistencies

\section{Disclosure}

The author declares no conflict of interest.

\section{References}

1. Launer J. Supervision, mentoring and coaching. Understanding medica education Evidence, theory and practice Oxford: Wiley Blackwell/ASME. 2014:111-22.

2. Kilminster S, Cottrell D, Grant J, Jolly B. AMEE Guide No. 27: Effective educational and clinical supervision. Med Teacher. 2007;29(1):2-19.

3. Bass EB, VI AHF, Morrison G, Wills S, Mumford LM, Goroll AH. National survey of clerkship directors in internal medicine on the competencies that should be addressed in the medicine core clerkship. Am J Med. 1997;102(6): 564-71.

4. Zeind CS, Zdanowicz M, MacDonald K, Parkhurst C, King C, Wizwer P. Developing a sustainable faculty mentoring program. Am J Pharm Educ. 2005;69(5):100.

5. Changiz T, Fakhari M, Jamshidian S, Zare S, Asgari F. Systematic review of studies in the field of competencies of new or soon to-be-graduate general physicians in Iran. sdmej. 2015;12(2).

6. Amiresmaili M, Nekoei Moghadam M, Moosazadeh M, Pahlavan E. Challenges of general practice education in Iran: A qualitative study. Strides Dev Med Educ. 2013;9(2):118-31.

7. Razmjou S, Baradaran HR, Kouhpayehzadeh J, Soltani-Arabshahi K. Comparison of quality of clinical supervision as perceived by attending physicians and residents in university teaching hospitals in Tehran. Med J Islamic Repub of Iran. 2015;29:248.

8. Kilminster S, Jolly BC. Effective supervision in clinical practice settings: a literature review. Med Educ. 2000;34(10):827-40.

9. Wimmers PF, Mentkowski M. Assessing competence in professional performance across disciplines and professions. Evaluating the Paradigm Shift from Time-Based Toward Competency-Based Medical Education (Chapter 19): Springer; 2016

10. Nasri K, Kahbazi M, Nourouzi A, Nasri S. The medical education problems and possible Solutions in stagers and intern's view points of Arak University of Medical Sciences. 2010:2006-07.

11. Shapiro SL, Shapiro DE, Schwartz GE. Stress management in medical education a review of the literature. Acad Med. 2000;75(7):748-59.
12. Ministry. Ministry of Health and Medical Education in IRAN,Doctor of Medicine Curriculum. Approved sixty-seventh meeting of the Supreme Council for Medical Planning 2018.

13. Yazdankhafard M, Poladi Sea. The stressors of clinical education from students' point of view in Bushehr University of Medical Sciences. Iran J Med Educ. 2008:8:341-50.

14. Caspi J, Reid WJ. Educational supervision in social work: A task-centered model for field instruction and staff development: Columbia University Press; 2002

15. Brunero $S$, Stein-Parbury J. The effectiveness of clinical supervision in nursing: an evidenced based literature review. Aust J Adv Nurs. 2008.

16. Bowles N, Young C. An evaluative study of clinical supervision based on Proctor's three function interactive model. J Adv Nurs. 1999;30(4):958-64.

17. Kadushin, editor Supervision in Social Work1976: New York and London. Columbia University Press.

18. Erera IP, Lazar A. Operationalizing Kadushin's model of social work supervision. J Social Service Res. 1994;18(3-4):109-22.

19. Inskipp F, Proctor B. The art, craft and tasks of counselling supervision, Part 1. Making the most of supervisors Twickenham, UK: Cascade Publications. 1993.

20. Morton-Cooper A, Palmer A. Mentoring, preceptorship, and clinical supervision: A guide to professional roles in clinical practice: University of Warwick.Blackwell Science; 2000

21. Clark P, Jamieson A, Launer J, Trompetas A, Whiteman J, Williamson D. Intending to be a supervisor, mentor or coach? Which, what for and why? Educ Primary Care. 2006:17(2):109-16.

22. Carnwell R, Daly W. Strategies for the construction of a critical review of the literature. Nurse Educ Pract. 2001:1(2):57-63.

23. Norman G, Eva KW. Quantitative research methods in medical education Understanding medical education Oxford, UK: Wiley-Blackwell. 2010:301-22.

24. Sterkenburg A, Barach P, Kalkman C, Gielen M, ten Cate O. When do supervising physicians decide to entrust residents with unsupervised tasks? Acad Med. 2010:85(9):1408-17. 
25. Hauer KE, ten Cate O, Boscardin C, Irby DM, lobst W, O'Sullivan PS Understanding trust as an essential element of trainee supervision and learning in the workplace. Adv Health Sci Educ. 2014;19(3):435-56.

26. LCME. Functions and structure of a medical school .standards for accreditation of medical education programs leading to the MD degree. Liaison Committee on Medical Education. 2014;28.

27. CACMS. Committee on Accreditation of Canadian Medical Schools (CACMS) Standards and Elements Effective 2018.

28. MCGILL. Supervision Policy for Trainees in the Clinical Team . The University of MC GILL Faculty of medicine , 2016 [Available from: https://mcgill.ca/ ugme/files/ugme/supervision_policy_for_trainees_in_clinical_team_ v1.1.pdf.

29. Alberta. Supervision of Medical Students on Clinical Rotations Policy. University of Alberta 2014 [Available from: https://www.ualberta.ca/ medicine/-/media/medicine/ume/policy/clinicalsupervision.pdf.

30. COLUMBIA. Expectations of Clinical Supervisors and Preceptors of Students in Clinical Settings. The University of British Columbia, 2018 [Available from: https://mednet.med.ubc.ca/AboutUs/PoliciesAndGuidelines/Policies\%20 Guidelines/Supervision\%20of\%20Students\%20in\%20\%20Required\%20 Clinical\%20Learning\%20Experiences\%20(031).pdf.

31. COLUMBIA. Expectations of Medical Students in Supervised Clinical Settings. The University of British Columbia 2017 [Available from: https:// mednet.med.ubc.ca/AboutUs/PoliciesAndGuidelines/Policies\%20 Guidelines/Supervision\%20of\%20Students\%20in\%20\%20Required\%20 Clinical\%20Learning\%20Experiences\%20(031).pdf.

32. Boston. Clinical Supervision Policy. Boston University School of Medicine, 2018 [Available from: https://www.bumc.bu.edu/busm/files/2018/11/ Clinical-Supervision-Policy.pdf.

33. Nebraska. Clinical Supervision of Medical Students. University of Nebraska College of Medicine (UNCOM), 2017 [Available from: https://www. unmc.edu/com/education/com-student-policies/com-policies/clinicalsupervision.htm/University

34. Florida. medical student roles and supervision policy.medical student handbook.Florida Atlantic University Charles E. Schmidt College of Medicine (FAU COM), 2019

35. Washington. Policy on Supervision of Medical Students in Clinical Settings. The University of Washington School of Medicine (UWSOM) 2017 [Available from: https://medicine.wsu.edu/documents/2017/08/clinical-supervisionof-medical-students.pdf/.

36. Carolina. Clinical Supervision of Medical Students. University of North Carolina School of Medicine (UNC SOM) 2019 [Available from: https://www. med.unc.edu/md/policies/files/2019/01/Clinical-Supervision-of-MedicalStudents-LCME-9.3.pdf.

37. Minnesota. Student Supervision During Clinical Activities. The University of Minnesota Medical School (UMMS), 2019 [Available from: https://med.umn. edu/sites/med.umn.edu/files/ocu.0119.006.1_student_supervision.pdf.

38. Pennsylvania. Supervision Of Medical Student Clinical Activity. (UPENN) 2019 [Available from: https://www.med.upenn.edu/flpd/assets/usercontent/documents/9.3\%20Medical\%20Student\%20Supervision\%20Policy. docx.

39. GMC. Developing teachers and trainers in undergraduate medical education. Advice Suppl Tomorrow's Doctors 2009:12.

40. PMETB. Generic standards for training: Postgraduate Medical Education and Training Board; 2008

41. RACGP. Guidelines for the Supervision of Medical Students in General Practice. The Royal Australian College Of General Practitioners (RACGP). 2007

42. Basa v. Models of supervision in therapy, brief defining features. Eur J Counsel Theory Res Pract. 2017;1(4):1-5.

43. Proctor B. Supervision: a cooperative exercise in accountability. in M Marken and MPayne (eds) Enabling and Ensuring Leicester: Leicester National Youth Bureau and Council

44. for Education and Training in Youth and Community Work. 1988b.

45. Kadushin A, Harkness D. Supervision in social work: Columbia University Press; 2002.

46. Morrison T. Staff supervision in social care: An action learning approach: Pavilion Publishing; 2001

47. Hawkins P, Shohet R. Supervision in the helping professions: McGraw-Hill Education (UK); 2012

48. Hughes JM. The role of supervision in social work: A critical analysis. Critic Soc Think Policy Pract. 2010;2:59-77.
49. Turner J, Hill A. Implementing clinical supervision (part 1): a review of the literature. Mental Health Nurs (Online). 2011:31(3):8.

50. Sloan G, Watson H. Clinical supervision models for nursing: structure, research and limitations. Nursing Stand (through 2013). 2002:17(4):41.

51. Gillieatt S, Martin R, Marchant T, Fielding A, Duncanson K. Evaluation of an inter-professional training program for student clinical supervision in Australia. Human Resour Health. 2014;12(60):1-9.

52. Butterworth TC, J.; White, E.;. It is good to talk An evaluation of clinical supervision and mentorship in England and Scotland. University of Manchester. GB_1997:12245; GB; 1997.

53. Morton-Cooper A, Palmer A. Mentoring, preceptorship and clinical supervision. Nurse Educ Today. 2000;20:418-21.

54. Butterworth T, Bishop V, Carson J. First steps towards evaluating clinical supervision in nursing and health visiting. I. Theory, policy and practice development. A review. J Clin Nurs. 1996:5(2):127-32.

55. Cutcliffe JR. An alternative training approach in clinical supervision. Routledge handbook of clinical supervision: Routledge; 2010. p. 63-78.

56. Jones A. Clinical supervision: a framework for practice. Int J Psychiatric Nurs Res. 1996;3:290-307

57. Tuck JA. A new approach to team clinical supervision on an acute admissions unit. Mental Health Pract. 2017;20(5).

58. Scaife J. Supervision in the mental health professions: A practitioner's quide: Routledge; 2003.

59. Patel P. An evaluation of the current patterns and practices of educational supervision in postgraduate medical education in the UK. Perspect Med Educ. 2016;5(4):205-14.

60. Chang S, Baldwin CD, Cameron C. Mentoring mentors in scientific communication for trainees. Acad Med J Assoc Am Med Coll. 2015:90(3):265-

61. Barker ER, Pittman O. Becoming a super preceptor: A practical guide to preceptorship in today's clinical climate. J Am Acad Nurse Pract. 2010;22(3):144-9

62. Landreville J, Cheung W, Frank J, Richardson D. A definition for coaching in medical education Can Med Educ J. 2019·10(4):e109.

63. Morton-Cooper A. Preceptorship via action research: a reflective account: University of Warwick; 1997 [Available from: https://ethos.bl.uk/ OrderDetails.do?uin=uk.bl.ethos.263611\%.

64. Rousseau M. Structured mentoring for sure success: PennWell Corp; 2008

65. Jarvis J. Coaching and buying coaching services: A guide: Chartered Institute of Personnel and Development; 2004.

66. Passi V. The importance of mentoring during educational supervision. Perspect Med Educ. 2016;5(4):195-6.

67. Johnson WB, Skinner CJ, Kaslow NJ. Relational mentoring in clinical supervision: The transformational supervisor. J Clin Psychol. 2014:70(11):1073-81.

68. Johnson WB. Transformational supervision: When supervisors mentor. Prof Psychol Res Pract. 2007;38(3):259

69. Gardner A, McCutcheon H, Fedoruk M. Superficial supervision: are we placing clinicians and clients at risk? Contemp Nurse. 2010;34(2):258-66.

70. Beddoe L. External supervision in social work: Power, space, risk, and the search for safety. Austr Social Work. 2012;65(2):197-213.

71. Council GM. Tomorrow's doctors: outcomes and standards for undergraduate medical education. Manchester, UK: General Medical Council. 2009.

72. PMETB. Operational Guide for the PMETB Quality Framework 2009 [Available from: http://www.pmetb.org.uk/fileadmin/user/QA/QF/QF_ Operational_Guide.pdf

73. GMC. General Medical Council.The Early Years. London: GMC1999.

74. Kennedy TJ, Regehr G, Baker GR, Lingard L. Preserving professional credibility: grounded theory study of medical trainees' requests for clinical support. Bmj. 2009;338:b128.

75. Farmer s Tn. Trainor nev supervision Chapter Four : Effective interventions with offenders 2016 [107]. Available from: http://www.hma.co.nz/wpcontent/uploads/2016/01/Chapter-4-Supervision.pdf.

76. Basa V. Supervisor-supervisee relationship and alliance. Eur J Counsel Theory Res Pract. 2017;1:1-5.

77. Lakey B, Tardiff TA, Drew JB. Negative social interactions: assessment and relations to social support, cognition, and psychological distress. J Soc Clin Psychol. 1994;13(1):42-62

This work is licensed under a Creative Commons Attribution-NonCommercial 3.0 Unported License which allows users to read, copy, distribute and make derivative works for non-commercial purposes from the material, as long as the author of the original work is cited properly. 